\title{
Appraising zinc bioaccumulation in abalone Haliotis diversicolor supertexta and alga Gracilaria tenuistipitata var. liui by probabilistic analysis
}

\author{
Chung-Min Liao ${ }^{\mathrm{a}, *}$, Min-Pei Ling ${ }^{\mathrm{a}}$, Jui-Sheng Chen ${ }^{\mathrm{b}}$ \\ ${ }^{a}$ Department of Bioenvironmental Systems Engineering, National Taiwan University, Taipei 10617, Taiwan, ROC \\ ${ }^{\mathrm{b}}$ Department of Environmental Engineering and Sanitation, Fooyin Institute of Technology, \\ Kaohsing 831, Taiwan, ROC
}

Received 4 January 2002; received in revised form 30 May 2002; accepted 24 June 2002

\begin{abstract}
We appraise a first-order two-compartment model describing zinc $(\mathrm{Zn})$ bioaccumulation in abalone Haliotis diversicolor supertexta and their food source, red alga Gracilaria tenuistipitata var. liui by probabilistic analysis of the biokinetic parameter variabilities. The model was parameterized using field and laboratory data, and predictions were quantitatively compared with field-measured tissue $\mathrm{Zn}$ concentrations obtained from selected abalone farms. Based on the reliable information from the published literature, we assigned the lognormal distribution model to characterize model inputs. Input variables included bioconcentration factor (BCF) of abalone, biomagnification factor of abalone, BCF of algae and depuration rate constants of abalone $\left(k_{2}\right)$ for $\mathrm{Zn}$ from water and food. Compared with the field data, most of the measurements fall within the predicted 25th and 75 th percentile range, indicating applying Monte Carlo technique to the first-order two-compartment model generated probabilistic estimates of $\mathrm{Zn}$ concentrations in abalone and algae that were consistent with field observations. Sensitivity analysis reveals that the input critical parameters that most influence the model output are BCF and $k_{2}$ of abalone. Our results suggest that the probabilistic approach allows a range of possible outcomes and their likelihood; it better informs both aquacultural risk assessors and risk managers. The degree of conservatism in the deterministic bioaccumulation models can also be evaluated against this distribution.

(C) 2003 Elsevier Science B.V. All rights reserved.
\end{abstract}

Keywords: Abalone; Algae; Bioaccumulation; Probabilistic analysis; Zinc

* Corresponding author. Tel.: +886-2-2363-4512; fax: +886-2-2362-6433.

E-mail address: cmliao@ccms.ntu.edu.tw (C.-M. Liao). 


\section{Introduction}

Abalone, Haliotis diversicolor supertexta, is the most abundant abalone species in Taiwan. H. diversicolor supertexta is commercially important for fisheries and aquaculture in Taiwan (Chen, 1989). H. diversicolor supertexta is appreciated for its delicacy and high market value. The aquaculture of $H$. diversicolor supertexta, thus, is a promising business (Chen, 1989; Singhagraiwan and Doi, 1993).

Zinc $(\mathrm{Zn})$ is an essential micronutrient found at high levels in the algae and in the tissues of fish/shellfish (Hogstrand et al., 1998; Genter and Lehman, 2000). Zinc is available to abalone from both the dissolved phase (e.g., gill uptake) and the diet (e.g., red alga Gracilaria tenuistipitata var. liui ingestion). If waterborne $\mathrm{Zn}$ levels are elevated, however, toxicity can occur and have severe effects on the health of abalone, which will reduce market prices and cause closure of abalone farms (Hahn, 1989; Conroy et al., 1996; Knauer et al., 1997).

Previous investigations indicated that $\mathrm{Zn}$ has been detected in many rivers and that maximum $\mathrm{Zn}$ concentrations in contaminated aquacultural waters are reported to range from 60 to $300 \mu \mathrm{g}^{-1}$ in different areas of Taiwan (Lee et al., 1996; Lin and Liao, 1999). Because few previous studies have evaluated $\mathrm{Zn}$ toxicity to $H$. diversicolor supertexta, we did not have an a priori estimate of internal lethal body burdens. Mechanisms of $\mathrm{Zn}$ toxicity in abalone have not been investigated extensively.

Vermeire et al. (2001) pointed out that probabilistic modeling has received increasing support as a promising technique for characterizing uncertainty and variation in estimates of exposure to environmental contaminants. To date, however, only a limited number of risk assessments regarding aquacultural management have incorporated probabilistic analyses. A predictive assessment is needed to evaluate the potential for $\mathrm{Zn}$ bioaccumulation, toxic effects to abalone and risks to human health. The determination of biokinetic parameters is an essential component in the risk assessment of potential harmful chemicals. A wellestablished one-compartment uptake-depuration model may provide realistic estimates of the biokinetic parameters such as uptake and depuration rate constants through a laboratory exposure experiment (Lin and Liao, 1999). The reliability of the predictive model, however, is determined by the precision of the model inputs. In order to assess how model predictions are affected by the uncertainties in biokinetic parameter values, we use the probability density function (pdf) to characterize biokinetic variables.

This paper applied a first-order two-compartment model to evaluate the importance of biokinetic variability in $\mathrm{Zn}$ bioaccumulation in abalone. The two-compartment model describes the processes of uptake and elimination of $\mathrm{Zn}$ in abalone between water and its food source, red alga G. tenuistipitata var. liui. The following three elements are used to perform a probabilistic analysis in the predictive bioaccumulation modeling: (1) to characterize the uncertainty on the selected biokinetic parameters influencing bioaccumulation, (2) to produce a Monte Carlo-simulated prediction of $\mathrm{Zn}$ concentrations in abalone and algae and to perform a sensitivity analysis to identify critical inputs and (3) to interpret the results in the light of uncertainty and to compare with published field studies obtained from three selected commercial abalone farms.

The probabilistic framework was selected because it overcomes certain limitations in the deterministic approach. In particular, the deterministic approach lacks any precise 
evaluation of the uncertainties and the conservation estimates implied in the results. The combination of a predictive bioaccumulation model and an uncertainty analysis would help to understand the biokinetic behavior of waterborne metals in abalone associated with the human health risk resulting from consumption of abalone.

\section{Materials and methods}

\subsection{Model structure}

We used a first-order two-compartment model to describe uptake and elimination processes of abalone exposed to $\mathrm{Zn}$ in an abalone-farming pond. Fig. 1 shows the processes considered in this study. The scenarios (Fig. 1) that we considered were (i) the exchange of $\mathrm{Zn}$ between abalone and dissolved $\mathrm{Zn}$ was modeled as a first-order process, with additional $\mathrm{Zn}$ accumulation from ingested algae; (ii) abalone ingest only algae and other suspended particles uptakes are negligible; (iii) tissue concentration of $\mathrm{Zn}$ per unit biomass of abalone increases as a result of direct uptake from water and through assimilation of algae; and (iv) tissue concentration tend to decrease as a result of elimination from the whole body.

The first-order two-compartment model for the gain and loss of $\mathrm{Zn}$ accumulation in abalone and algae features constant biokinetic rates and constant water concentration.

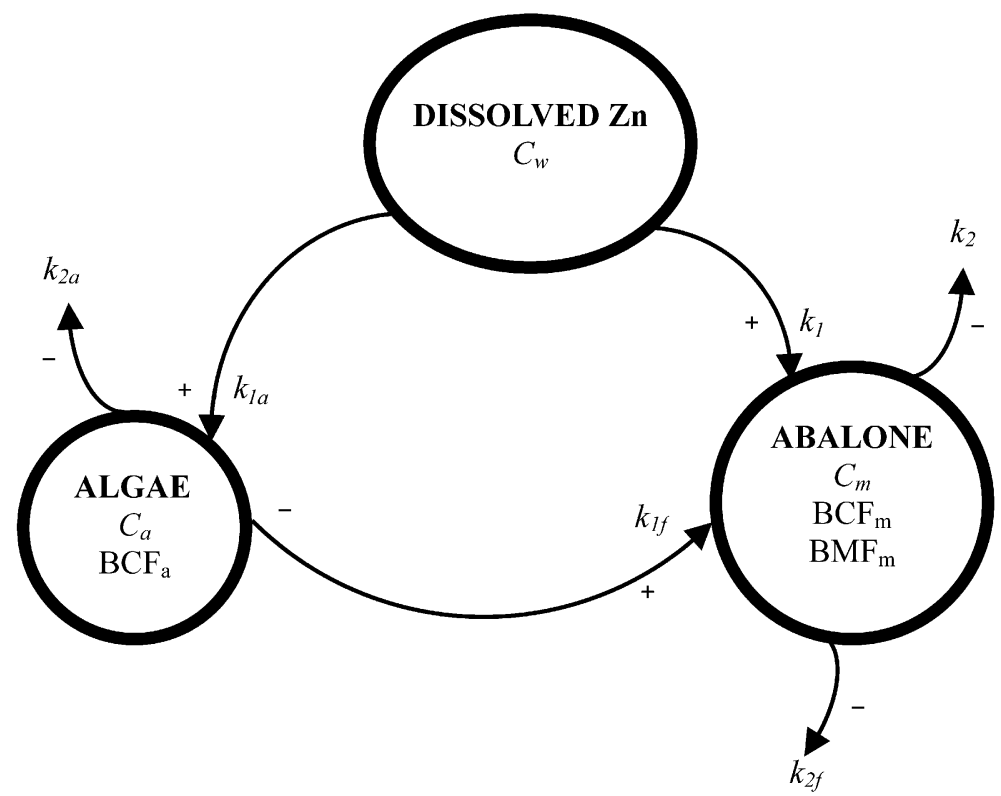

Fig. 1. Schematic showing the first-order two-compartment model of $\mathrm{Zn}$ bioaccumulation in abalone H. diversilor supertexta and their food red alga G. tenuistipitata var. lilu (see Eqs. (1) and (2) for full explanation). 
Accordingly, the dynamic behavior corresponding to the graphic model of Fig. 1 would be represented as

$$
\begin{aligned}
& \frac{\mathrm{d} C_{\mathrm{m}}(t)}{\mathrm{d} t}=k_{1} C_{\mathrm{w}}+k_{1 \mathrm{f}} C_{\mathrm{a}}(t)-\left(k_{2}+k_{2 \mathrm{f}}\right) C_{\mathrm{m}}(t), \\
& \frac{\mathrm{d} C_{\mathrm{a}}(t)}{\mathrm{d} t}=k_{1 \mathrm{a}} C_{\mathrm{w}}-\left(k_{2 \mathrm{a}}+k_{1 \mathrm{f}}\right) C_{\mathrm{a}}(t),
\end{aligned}
$$

where $\mathrm{C}_{\mathrm{m}}(t)$ is the time-dependent $\mathrm{Zn}$ concentration in abalone soft tissue $\left(\mu \mathrm{g} \mathrm{g}^{-1}\right), C_{\mathrm{a}}(t)$ is the time-dependent $\mathrm{Zn}$ concentration in algae $\left(\mu \mathrm{g} \mathrm{g}^{-1}\right), t$ is the time of exposure (day), $C_{\mathrm{w}}$ is the dissolved $\mathrm{Zn}$ concentration in water $\left(\mu \mathrm{g} \mathrm{g}^{-1}\right), k_{1}$ is the uptake rate constant from dissolved phase by abalone $\left(\mathrm{ml} \mathrm{g}^{-1}\right.$ day $\left.^{-1}\right), k_{1 \mathrm{f}}$ is the uptake rate constant from algae by abalone $\left(\mathrm{g} \mathrm{g}^{-1}\right.$ day $\left.^{-1}\right), k_{2}$ is the depuration rate constant for $\mathrm{Zn}$ in abalone (day $\left.{ }^{-1}\right), k_{2 \mathrm{f}}$ is the elimination rate constant for $\mathrm{Zn}$ from food in abalone $\left(\right.$ day $\left.^{-1}\right), k_{1 \mathrm{a}}$ is the uptake rate constant from dissolved $\mathrm{Zn}$ by algae $\left(\mathrm{ml} \mathrm{g}^{-1}\right.$ day $\left.{ }^{-1}\right)$ and $k_{2 \mathrm{a}}$ is the depuration rate constant for $\mathrm{Zn}$ in algae $\left(\right.$ day $^{-1}$ ).

We consider the steady-state condition in Eq. (2) and solve for $C_{\mathrm{a}}$ gives,

$$
C_{\mathrm{a}}=\frac{k_{1 \mathrm{a}}}{k_{2 \mathrm{a}}+k_{1 \mathrm{f}}} C_{\mathrm{w}}=\mathrm{BCF}_{\mathrm{a}} C_{\mathrm{w}}
$$

where $\mathrm{BCF}_{\mathrm{a}} \equiv C_{\mathrm{a}} / C_{\mathrm{w}}=k_{1 \mathrm{a}} /\left(k_{2 \mathrm{a}}+k_{1 \mathrm{f}}\right)$ is the bioconcentration factor (BCF) for algae $(\mathrm{ml}$ $\mathrm{g}^{-1}$ ). By substituting Eq. (3) into Eq. (1), and solving for $C_{\mathrm{m}}(t)$ gives,

$$
C_{\mathrm{m}}(t)=C_{\mathrm{m}}(t=0) e^{-k_{\mathrm{e}} t}+\frac{k_{\mathrm{u}}}{k_{\mathrm{e}}} C_{\mathrm{w}}\left(1-e^{-k_{\mathrm{e}} t}\right),
$$

where $k_{\mathrm{u}}$ and $k_{\mathrm{e}}$ represent the overall uptake and overall elimination rate constants and have the form as,

$$
\begin{aligned}
& k_{\mathrm{u}}=k_{1}+k_{1 \mathrm{f}} \mathrm{BCF}_{\mathrm{a}}, \\
& k_{\mathrm{e}}=k_{2}+k_{2 \mathrm{f}} .
\end{aligned}
$$

The $\mathrm{Zn}$ concentration in abalone is calculated as $C_{\mathrm{m}}=k_{\mathrm{u}} / k_{\mathrm{e}} C_{\mathrm{w}}=\mathrm{BAF}_{\mathrm{m}} C_{\mathrm{w}}$ when equilibrium is achieved in Eq. (4) in that we define $\mathrm{BAF}_{\mathrm{m}} \equiv k_{\mathrm{u}} / k_{\mathrm{e}}$ and has a form as,

$$
\mathrm{BAF}_{\mathrm{m}}=\frac{k_{\mathrm{u}}}{k_{\mathrm{e}}}=\frac{\mathrm{BCF}_{\mathrm{m}}}{1+k_{2 \mathrm{f}} k_{2}^{-1}}+\mathrm{BMF}_{\mathrm{m}} \mathrm{BCF}_{\mathrm{a}},
$$

where $\mathrm{BAF}_{\mathrm{m}}$ is the bioaccumulation factor $(\mathrm{BAF})$ for abalone $\left(\mathrm{ml} \mathrm{g}{ }^{-1}\right), \mathrm{BCF}_{\mathrm{m}}=k_{1} / k_{2}$ is the $\mathrm{BCF}$ for abalone $\left(\mathrm{ml} \mathrm{g}^{-1}\right)$ and $\mathrm{BMF}_{\mathrm{m}}=k_{1 \mathrm{f}} / k_{\mathrm{e}}$ is the biomagnification factor (BMF) for abalone.

The input variables needed to model the $\mathrm{Zn}$ bioaccumulation in abalone and algae include abalone bioconcentration factor $\mathrm{BCF}_{\mathrm{m}}$, abalone biomagnification factor $\mathrm{BMF}_{\mathrm{m}}$, algae bioconcentration factor $\mathrm{BCF}_{\mathrm{a}}$ and biokinetic parameters of abalone elimination rate constant for $\mathrm{Zn}$ form food $k_{2 \mathrm{f}}$ and abalone depuration rate constant for $\mathrm{Zn} k_{2}$. 


\subsection{Input probability distributions}

Parameterization of the model involved selecting data sets and deriving input distributions. Current literature was reviewed to develop probability distributions for the random variables appearing in the bioaccumulation model adopted. Source data of biokinetic parameters appeared in Eqs. (1) and (2) would be obtained from a published study by Chen (1984, 1989), Lee et al. (1996), Lin and Liao (1999) and Chen and Lee (1999). Data were sorted by reported statistical measure, e.g., mean, minimum, maximum, etc. Table 1 summarizes the estimated biokinetic parameters $\left(\mathrm{BCF}_{\mathrm{m}}, k_{2 \mathrm{f}}\right.$ and $\left.k_{2}\right)$ that were determined from a 14-day laboratory uptake-depuration experiment and field observations for $\mathrm{BMF}_{\mathrm{m}}$ and $\mathrm{BCF}_{\mathrm{a}}$ obtained from real abalone farms. Wherever possible, we tried to account for uncertainty in these estimates. Table 1 gives the published biokinetic data as the mean $(\mu)$ with one deviation $(\sigma)$ represented as 1 S.E. or $95 \%$ confidence limits $(95 \%$ c.1.).

The goal of the distribution selection process for each input variables was to identify a mathematical distribution expressing the range of variation and likelihood of values within the range. The normal distribution function is rarely used to account for the uncertainty in estimates because smooth symmetric variation of mean values is unexpected and data might be insufficient for estimating a mean and standard deviation since individual measurements reflecting interindividual variation about that mean, due to environmental or physical factors. A second problem in applying the normal distribution to any quantity that varies over a wide range is that such a wide normal distribution requires a certain fraction of the parameters to have negative values. This problem combined with the frequently observed skewed shape of the distribution, led to the use of the logarithmic transformation of parameter data to obtain the lognormal distribution.

Table 1

Estimates of input biokinetic parameters obtained from published data and geometric mean and geometric standard deviation for each parameter modeled as a lognormal distribution for the model simulation

\begin{tabular}{|c|c|c|c|c|}
\hline \multirow[t]{2}{*}{$\begin{array}{l}\text { Biokinetic } \\
\text { variable }^{\mathrm{a}}\end{array}$} & \multirow[t]{2}{*}{$\begin{array}{l}\text { Deterministic } \\
\text { parameter values }\end{array}$} & \multirow[t]{2}{*}{ Ref. } & \multicolumn{2}{|c|}{$\begin{array}{l}\text { Parameter of the lognormal } \\
\text { distributions employed }\end{array}$} \\
\hline & & & Geometric mean & Geometric S.D. \\
\hline$k_{2}\left(\right.$ day $\left.^{-1}\right)$ & $0.611 \pm 0.53^{\mathrm{b}}$ & Lin and Liao (1999) & 0.437 & 4.13 \\
\hline$k_{2 \mathrm{f}}\left(\right.$ day $\left.^{-1}\right)$ & $0.636 \pm 0.26^{\mathrm{b}}$ & Lin and Liao (1999) & 0.602 & 1.53 \\
\hline $\mathrm{BCF}_{\mathrm{m}}\left(\mathrm{ml} \mathrm{g}^{-1}\right)$ & $166 \pm 16^{\mathrm{c}}$ & Lin and Liao (1999) & 165.22 & 1.10 \\
\hline $\mathrm{BMF}_{\mathrm{m}}\left(\mathrm{g} \mathrm{g}^{-1}\right)$ & $\begin{array}{l}1.53 \pm 0.25^{\mathrm{c}} \\
(1.09,1.87)^{\mathrm{d}}\end{array}$ & $\begin{array}{l}\text { Chen (1984, 1989), } \\
\text { Lin and Liao (1999), } \\
\text { Chen and Lee (1999) }\end{array}$ & 1.51 & 1.19 \\
\hline $\mathrm{BCF}_{\mathrm{a}}\left(\mathrm{ml} \mathrm{g}^{-1}\right)$ & $\begin{array}{l}524 \pm 149^{c} \\
(329,698)^{d}\end{array}$ & $\begin{array}{l}\text { Lee et al. (1996), } \\
\text { Lin and Liao (1999), } \\
\text { Chen and Lee (1999) }\end{array}$ & 501.00 & 1.39 \\
\hline
\end{tabular}

\footnotetext{
${ }^{\mathrm{a}} k_{2}$ is the depuration rate constant for $\mathrm{Zn}$ in abalone, $k_{2 \mathrm{f}}$ is the elimination rate constant for $\mathrm{Zn}$ from food in abalone, $\mathrm{BCF}_{\mathrm{m}}$ is the bioconcentration factor for abalone, $\mathrm{BMF}_{\mathrm{m}}$ is the biomagnification factor for abalone and $\mathrm{BCF}_{\mathrm{a}}$ is the bioconcentration factor for algae.

b Mean $\pm 95 \%$ confidence limit.

c Mean \pm S.E.

$\mathrm{d}$ Values are (minimum, maximum).
} 
Moreover, the lognormal distribution is often considered the default in environmental analysis (Finley et al., 1994; Thompson et al., 2000). Its extensive use may be explained by the fact that environmental processes involve products of several variables, which suggests applicability of the central limit theorem upon logarithmic transformation (Johnson et al., 1995; Balthis et al., 1996; El-Shaarawi and Viverros, 1997; Vermeire et al., 2001; Jager et al., 2001). The data are divided into a minimum of 10 bins as equally as possible, based on a normal distribution in that the mean and S.E. or $95 \%$ c. 1 . are shown in Table 1.

We used the chi-square $\left(\chi^{2}\right)$ and the Kolmogorov-Smirnov (K-S) statistics (Zar, 1999) to optimize the goodness-of-fit of distributions. Data and distribution parameters were analyzed and estimated using the Statistica ${ }^{\circledR}$ software package (StatSoft, Tulsa, OK, USA). The Statistica ${ }^{\circledR}$ software generated $p$-values for the $\chi^{2}$ statistics and provided critical values of $d_{\max }$ for the $\mathrm{K}-\mathrm{S}$ statistics to estimate $\alpha$ values from 0.01 to 0.50 . For optimization, $p \geq 0.05$ considered good, $p=0.05-0.10$ was acceptable and $p<0.10$ was poor. We determined that the lognormal distribution model fits the observed data favorably and were transformed appropriately to ensure the data did not differ from a normal distribution before parametric analysis. All input variables that modeled as the lognormal distributions from which geometric mean (gm: $\mu_{\mathrm{g}}$ ) and geometric standard deviation (gsd: $\sigma_{\mathrm{g}}$ ) for each variable was calculated (Table 1 ). Table 1 indicates that parameter variability $\left(\sigma_{\mathrm{g}}\right)$ of the estimate in $k_{2}$ is broader than that in $k_{2 \mathrm{f}}, \mathrm{BCF}_{\mathrm{m}}, \mathrm{BMF}_{\mathrm{m}}$ and $\mathrm{BCF}_{\mathrm{a}}$ in that variability determines the contribution of an input to the variance of model predictions.

Fig. 2 illustrates pdfs of the optimized lognormal distribution with gm and gsd $\left(\ln \left(\mu_{\mathrm{g}}\right.\right.$, $\left.\sigma_{\mathrm{g}}\right)$ ) for five of the model inputs. The histograms of source data with frequency functions of the normal distribution $(\mathrm{N}(\mu, \sigma))$ are also shown. Therefore, we suggest that random variables characterizing uncertainty about any model input biokinetic variable $x$ has a lognormal pdf with gm $\left(\sigma_{\mathrm{g}, x}\right)$ and $\operatorname{gsd}\left(\mu_{\mathrm{g}, x}\right)$ as $x \sim f_{x}(x) \equiv \ln \left(\mu_{\mathrm{g}, x}, \rho_{\mathrm{g}, x}\right)$ in that

$$
f_{x}(x)=\frac{1}{\sqrt{2 \pi} x \ln \sigma_{\mathrm{g}, x}} \exp \left(-\frac{\left(\ln x-\ln \mu_{\mathrm{g}, x}\right)^{2}}{2\left(\ln \sigma_{\mathrm{g}, x}\right)^{2}}\right),
$$

and the cumulative distribution function (cdf) can be expressed as

$$
F_{x}(x)=\Phi\left(\frac{\ln x-\ln \mu_{\mathrm{g}, x}}{\ln \sigma_{\mathrm{g}, x}}\right),
$$

where $\Phi(\cdot)$ is the cdf of the standard normal random variable.

\subsection{Sensitivity analysis and validation}

We are interested in the long-term equilibrium rather than the dynamics over a single growing season. We used Eqs. (3) and (4) to predict $\mathrm{Zn}$ concentrations in abalone and algae. Because the idea of the present model was to incorporate uncertainty into the model by selecting model parameters from lognormal probability distributions rather than experimentally derived values or field observations, we used a Monte Carlo technique to deal with the uncertainty (Vose, 2000). To test the convergence and the stability of the numerical output, we performed independent runs at 1000, 4000, 5000 and 10,000 iterations with each 



Fig. 2. Probability density functions of optimized lognormal distribution with geometric mean $\left(\mu_{\mathrm{g}}\right)$ and geometric standard deviation $\left(\sigma_{\mathrm{g}}\right)$ as $\ln \left(\mu_{\mathrm{g}}, \sigma_{\mathrm{g}}\right)$ for five model inputs. The histogram of source data with frequency functions of the normal distribution are also shown.

parameter sampled independently from the appropriate distribution at the start of each replicate. Largely because of limitations in the data used to derive model parameters, inputs were assumed to be independent. The coefficient of variation (the ratio of standard deviation to mean for each number of iterations) was computed, with the conclusion that 5000 iterations are sufficient to ensure the stability of results. In this case, the numerical error on the 95th percentile is equal to $2 \%$. Sokal and Rohlf (1995) also indicated that more than 1000 replicate simulations gives $\mathrm{K}-\mathrm{S} 95 \%$ confidence limits of approximately $\pm 4 \%$ on output distributions and should be sufficient to ensure reliable results.

One step in trying to establish the range of conditions under which a model may be considered reliable is to identify components of the model that are important to model 
results. If parameters of great importance to model output are well established experimentally or in the field, then the reliability of the model is strengthened. Alternatively, if the most important parameters are those that are less well-established, then future research should be focused on those parameters to improve the predictive capabilities of the model. To this purpose, a sensitivity analysis was performed in order to determine which pdfs have the greatest effect on model results. Therefore, the final results were analyzed statistically to identify the key parameters causing the model to reproduce the observed behavior.

The theory behind this sensitivity analysis is based on the separation between the baseline and shifted (mean or variance shifts) cumulative distribution functions (cdfs), and a $\mathrm{K}-\mathrm{S}$ two-sample test is utilized to assess the separation (Hornberger and Spear, 1980; Spear and Hornberger, 1980). The statistic $d_{\max }$ is determined as the maximum vertical distance between the cdf curves for baseline and shifted functions. The large values of $d_{\text {max }}$ indicate that the parameter is important for simulating the model. The cdf curves also highlight if the values of the parameters causing the model outputs were at the lower or upper bounds or around the midpoint of the range.

Model predictions were compared to measurements of $\mathrm{Zn}$ concentration in algae and soft tissue of abalone at three different abalone farms on Toucheng, Kouhu, and Anping, in northern, central, and southern Taiwan region, respectively, to evaluate the predictive ability of the model. Lin and Liao (1999) chose three appropriate management practices on abalone farms for each study location and measured $\mathrm{Zn}$ concentrations in pond water, algae and abalone, respectively. Three abalone, three algae samples, and three 500-ml water samples per farm were collected. The nine abalone farms had similar feeding strategies and the biomass of algae and abalone were monitored throughout each growing season by the farm owners.

Simulations were run with each reported water $\mathrm{Zn}$ concentration measurements (cdfs of water $\mathrm{Zn}$ concentration were also lognormal-transformed from field data), using the inputs listed in Table 1. No other studies containing suitable data were identified, thus, extremely limited field data are available for model validation.

\section{Results}

Fig. 3 shows the pdfs and cdfs of $\mathrm{Zn}$ in abalone and algae for abalone farms of Toucheng, Kouhu and Anping. Probabilistic simulations of the bioaccumulation models produced skewed distributions of predicted $\mathrm{Zn}$ concentrations. Percentile predictions of $\mathrm{Zn}$ in abalone and algae in each abalone farm could be determined from cdfs illustrated in Fig. 3. Table 2 gives the percentile predictions of $\mathrm{Zn}$ concentrations in abalone and algae for three selected abalone farms. We also used box and whisker plot to represent the uncertainty in estimates of $\mathrm{Zn}$ concentration in abalone and algae (Fig. 4). Compared with the field observations, median estimates of $\mathrm{Zn}$ in abalone and algae were less than

Fig. 3. Simulation results showing probability density functions and cumulative distribution functions of $\mathrm{Zn}$ concentrations in $H$. diversilor supertexta and G. tenuistipitata var. lilu for three selected abalone farms: (A) Toucheng, (B) Kouhu and (C) Anping. (A) Measured mean concentration in H. diversilor supertexta. ( $\nabla)$ Measured mean concentration in G. tenuistipitata var. lilu. 

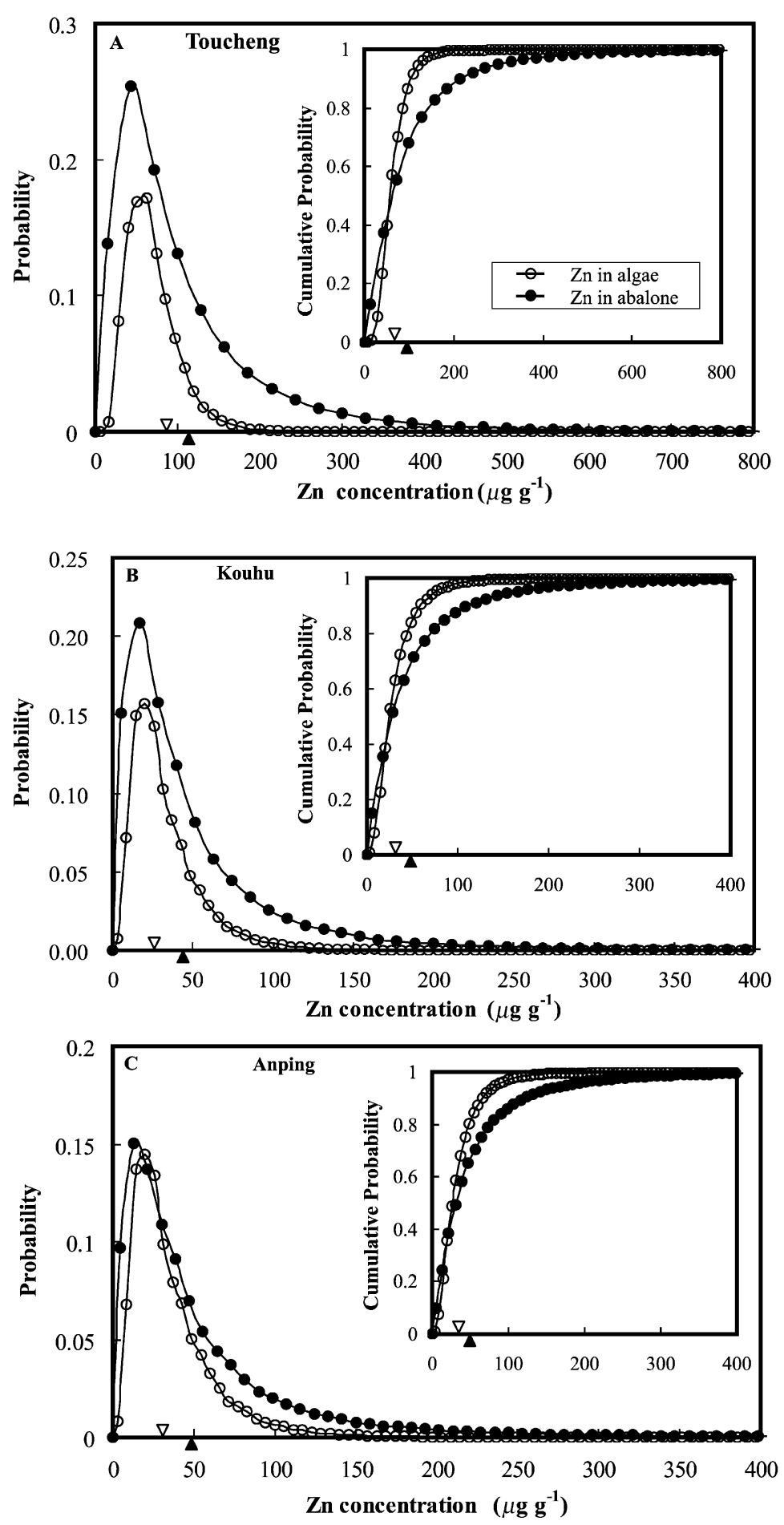
Table 2

Percentile predictions of $\mathrm{Zn}$ concentration $\left(\mu \mathrm{g} \mathrm{g}^{-1}\right)$ in algae and abalone in abalone farms located at Toucheng, Kouhu and Anping

\begin{tabular}{|c|c|c|c|c|c|c|c|c|}
\hline \multirow[t]{2}{*}{ Abalone farm } & \multicolumn{3}{|c|}{ Field observations ${ }^{\mathrm{a}}$} & \multicolumn{5}{|c|}{ Percentile predictions } \\
\hline & Mean & S.E. & (Min, $\max$ ) & 10th & 25 th & 50 th & 75th & 90th \\
\hline \multicolumn{9}{|l|}{ Toucheng } \\
\hline Water & 131.04 & 31.99 & & & & & & \\
\hline Abalone & 111.00 & & $(93.45,121.45)$ & 10.21 & 24.89 & 61.95 & 121.87 & 218.42 \\
\hline Algae & 91.04 & & $(52.84,111.08)$ & 30.00 & 41.29 & 58.33 & 79.86 & 104.52 \\
\hline \multicolumn{9}{|l|}{ Kouhu } \\
\hline Water & 60.71 & 21.60 & & & & & & \\
\hline Abalone & 46.41 & & $(38.21,53.47)$ & 4.57 & 11.74 & 26.96 & 58.03 & 110.23 \\
\hline Algae & 25.44 & & $(21.78,32.39)$ & 9.65 & 15.05 & 24.89 & 38.98 & 59.04 \\
\hline \multicolumn{9}{|l|}{ Anping } \\
\hline Water & 69.59 & 32.23 & & & & & & \\
\hline Abalone & 49.77 & & $(44.95,58.21)$ & 4.39 & 13.71 & 31.07 & 64.86 & 120.87 \\
\hline Algae & 31.93 & & $(20.77,45.98)$ & 9.93 & 16.25 & 26.77 & 43.35 & 66.11 \\
\hline
\end{tabular}

The field observations are also shown as mean ( $\min , \max )$, whereas measured water Zn concentrations $\left(\mu \mathrm{g} 1^{-1}\right)$ are shown as mean with 1 S.E. $(n=9)$.

a Adapted from Lin and Liao (1999).

measured mean values (Table 2). Five of six field observations of three selected abalone farms are within the predicted 25th and 75th percentile range, and all fall within the 10th and 90th percentile range (Table 2). Therefore, applying the Monte Carlo technique to the first-order two-compartment model generated probabilistic estimates of $\mathrm{Zn}$ concentrations

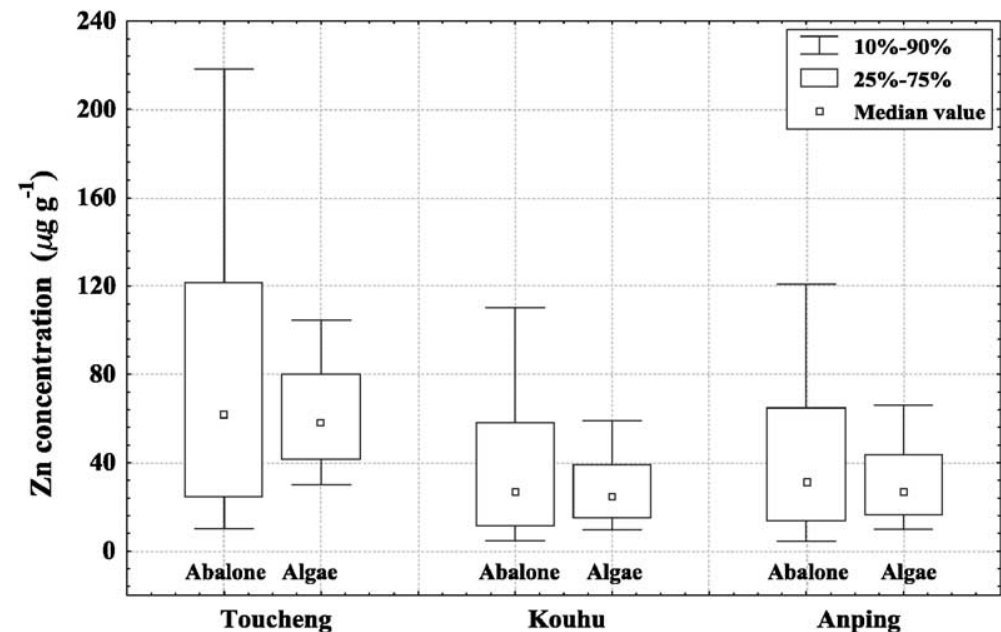

Abalone farm

Fig. 4. Box and whisker plot representations of Zn concentration in H. diversilor supertexta and G. tenuistipitata var. lilu collected from abalone farms in Toucheng, Kouhu and Anping. 




Fig. 5. Overall display of probabilistic distributions of predicted $\mathrm{Zn}$ concentrations in $H$. diversilor supertexta and G. tenuistipitata var. lilu subject to measured water $\mathrm{Zn}$ concentration at three selected abalone farms located at north, central and south Taiwan region, respectively.

in abalone and algae that were consistent with field data. Relative to minimum and maximum field data, however, lower and upper probabilistic percentile predictions were more conservative. It is evidence that the modeling framework and the distributional parameters and assumptions in the model are appropriate for estimating bioaccumulation of $\mathrm{Zn}$ in abalone and algae.

Although those cdfs for $\mathrm{Zn}$ in abalone and algae present in Fig. 3 are equally acceptable, they have different meanings. Risk associated with abalone exposure to $\mathrm{Zn}$ in allowable residue concentration in Toucheng abalone farm has a greater likelihood of occurrence than the same risk associated with exposure to $\mathrm{Zn}$ in Kouhu and Anping. The comparison of median values of pdfs shows that abalone and algae exposure to $\mathrm{Zn}$ will

Table 3

Kolmogorov-Smirnov test for sensitivity analysis of model parameters significant at $95 \%$ level $(0.152)$ or greater

\begin{tabular}{lll}
\hline Parameter & Description & $d_{\max }$ \\
\hline $\mathrm{BCF}_{\mathrm{m}}$ & Bioconcentration factor for abalone & 0.194 \\
$k_{2}$ & Depuration rate constant for Zn in abalone & 0.183 \\
$k_{2 \mathrm{f}}$ & Elimination rate constant for Zn from food in abalone & 0.177 \\
\hline
\end{tabular}


cause, on average, the same risk in each selected abalone farms; and all estimated tissue $\mathrm{Zn}$ concentrations have a higher uncertainty as quantified by the variance.

The relative skewness and spread in modeled output varied among water, abalone and algae; distributions of $\mathrm{Zn}$ concentrations in abalone were more highly skewed, with a long tail at higher concentrations (Fig. 3). Some median tissue concentrations generated by probabilistic method were close to mean values. Measurements of minimum and maximum were less widely spaced, or less conservative, than the 10th and 90th percentile values of probabilistic output. An overall display of distributions of predicted $\mathrm{Zn}$ concentrations in abalone and algae by abalone farm locations is illustrated in Fig. 5.

In view of Fig. 2, abalone depuration rate constant $k_{2}$ has a higher uncertainty as quantified by the variance (i.e., parameter variability: $\sigma_{\mathrm{g}}$ ), therefore, we assigned a variance shift for $k_{2}$, the other four parameters $\left(\mathrm{BCF}_{\mathrm{m}}, k_{2} \mathrm{f}, \mathrm{BMF}_{\mathrm{m}}\right.$ and $\left.\mathrm{BCF}_{\mathrm{a}}\right)$ are assigned as a mean shift. Based on the shift mappings for cdfs, the parameters and corresponding $d_{\text {max }}$ statistics that are significant above the 95\% level are listed in Table 3 . The parameters listed are mainly those directly controlling the model outputs because the probability model incorporated five stochastic variables in the calculation of $\mathrm{Zn}$ concentrations in abalone (Eq. (7)). Simulated Zn concentrations in abalone were most sensitive to abalone bioconcentration factor $\mathrm{BCF}_{\mathrm{m}}$, abalone depuration rate constant $k_{2}$, and abalone food elimination rate constant $k_{2 \mathrm{f}}$ (Table 3). Biomagnification factor for abalone $\mathrm{BMF}_{\mathrm{m}}$ and algae bioconcentration factor $\mathrm{BCF}_{\mathrm{a}}$ have values of 0.068 and 0.059 , respectively, and as such are not significant even at the $90 \%$ level (0.102).

Therefore, for $\mathrm{Zn}$ accumulation in abalone, the bioconcentration factor and depuration rate constant of abalone are the most influential variables (Table 3). This information implies that the mean value chosen in the deterministic bioaccumulation model for $\mathrm{BCF}_{\mathrm{m}}$ and $k_{2}$ contribution to $\mathrm{Zn}$ accumulation in abalone may not be sufficiently conservative: It will lead to $\mathrm{Zn}$ in abalone associated with a probability of exceeding a specific value of $\mathrm{Zn}$, higher than the threshold considered acceptable in the probabilistic context. For example, if the $\mathrm{BCF}_{\mathrm{m}}$ mean value corresponds to the $75 \%$ percentile of this parameter distribution; the allowable concentrations for $\mathrm{Zn}$ in abalone are strongly influenced by $\mathrm{BCF}_{\mathrm{m}}$, and the resulting $75 \%$ level of conservatism implied in the mean value is insufficient to ensure a $90 \%$ level of conservatism in the specific risk value calculated in the deterministic context.

\section{Discussion}

Based on the available data, the ranges of $\mathrm{Zn}$ concentrations in abalone and algae are overestimated within 75th and 90th precentiles, although median $\mathrm{Zn}$ concentrations predicted did not exceed observations and most observations were between 25 th and 70 th percentile predictions. Mean field data and median probabilistic predictions were similar in magnitude and minimum and maximum field data were much more narrowly spaced than the 10th and 90th percentile probabilistic predictions. This resulted from grouping probabilistic extreme minimum and maximum values in field data, which usually leads to unconservatism in exposure and risk estimates. Probabilistic 10th and 90th percentile 
estimates yielded slightly more relevant bounds of bioaccumulation in abalone since parameters were sampled independently in the probabilistic simulations. Overpredictions may result from many reasons, in particular, complex partitioning of $\mathrm{Zn}$ between water, suspended solid, and nonlinear accumulation of ionic metals in abalone and algae (Knauer et al., 1997). The model dose seems to represent the correct trends of $\mathrm{Zn}$ bioaccumulation.

Based on the contribution of key biokinetic parameters to output variance as determined in sensitivity analysis, the most important biokinetic variables are BCF and depuration/elimination rate constants $\left(k_{2}\right.$ and $\left.k_{2 \mathrm{f}}\right)$ in abalone. These variables are worth examining closely. Available data seem to provide reasonable measures of central tendency, but replication is limited and variation is not well represented. Because its $\sigma_{\mathrm{g}}$ is large, $k_{2}$ has a certain impact on output variance. By using constant water concentrations and varying BCFs independently, our model reveals that the BCFs for metals in abalone are higher than that in algae, suggesting that BCFs of $\mathrm{Zn}$ in abalone may be positively correlated with dissolved concentrations in water. Moreover, sensitivity analysis shows that the contribution of $\mathrm{BCF}_{\mathrm{m}}$ to overall accumulation is large in abalone, thus, considering the water route in abalone would appreciably affect estimates of total accumulation. Bertine and Goldberg (1972) and Amiard-Triquet et al. (1987) indicated that the levels of $\mathrm{Zn}$ in the algae-grazing mollusk, Gibbula umbillicalis and Littorina littorea, are not different from Zn level in a brown alga, Fucus serratus, that is the food species of the mollusks, indicating $\mathrm{Zn}$ in the abalone comes from the ambient water and not from the algae. Lin and Liao (1999) also pointed out that uptake of Zn from water by abalone is more significant compared with uptake from food. Therefore, when considering the aquaculture of abalone, it is a priority to control $\mathrm{Zn}$ concentration in the pond water.

The probabilistic methods used show that field data or experimentally derived values may hide significantly different levels of conservatism in relation to the uncertainty and variability present in each biokinetic parameter. Variation and uncertainty in model inputs were addressed using conservative assumptions, a range of abalone farm scenarios, and probabilistic analysis. The analysis does not reflect all source of uncertainty. Voit and Schubauer-Berigan (1998) pointed out that probabilistic analysis dose not account for structural errors in the model or inaccurate distributions of input variables. Although assuming independence among inputs is a common assumption in probabilistic analyses for initial analyses and when data sufficient to derive correlation coefficients are unavailable, biases may result that account for some of the overprediction of 75 th percentile in the present study. Indeed extrapolations from laboratory and field data are both uncertain and may underestimate variability. Consequently, in this application, probabilistic analysis may not provide accurate estimates of the distribution of $\mathrm{Zn}$ concentrations or risks, for example in 90th percentile concentrations. Furthermore, because model inputs were widely dispersed and lognormal distributed, predictions were right-skewed and spanned large ranges.

Presumably, centers of distribution are more realistic than tails and, thus, the analysis emphasizes 50th to 70th percentile predictions. Fortunately, available field data allow validation over the range of model outputs, including the upper percentile predictions. The model provides preliminary estimates of such statistic and this information is valuable because it can be used to guide future analysis and data collection efforts. In fact, though requiring more resources and skills, a Monte Carlo analysis carried out was very 
informative since it revealed the degree of conservatism and took into account the reliability of results.

The possibility to perform a detailed and more precise sensitivity analysis is an advantage that the probabilistic method provides relative to the deterministic one. Sensitivity analysis indicates that to increase the accuracy of the results efforts should focus on a better definition of probability distributions for abalone bioconcentration factor, depuration and food elimination rate constants. Given the scarcity of data, most of the probability distributions were based on limited observations from abalone farms, and this may be a limit to the validity of the case presented.

In summary, this paper illustrates the use of probabilistic distributions for various biokinetic and exposure factors in the context of a mechanistic bioaccumulation model that is amenable to probabilistic analyses for $\mathrm{Zn}$ accumulation in abalone and in their food source in the abalone farms.

Our results demonstrate that probabilistic simulations of the bioaccumulation model generated probabilistic distributions of tissue $\mathrm{Zn}$ concentrations that are generally consistent with field observations. The lower and upper probabilistic percentiles of $\mathrm{Zn}$ concentrations in abalone and algae were conservative relative to minimum and maximum observations in three selected abalone farms. Although these wide prediction ranges are limited in precision, applying such conservative ranges in calculated tissue burdens may be useful for modeling exposures to human consumption in risk assessments. Our model suggests that a simpler statistic-based model, such as empirical regression of BCFs, may generate more accurate predictions of bioaccumulation and be easier to parameterize. The mechanistic bioaccumulation model, however, can be a promising tool for increasing the understanding of heavy metals in aquacultural species as they are tested and refined.

It is our opinion that the incorporation of probabilistic analysis into evaluation of accumulation greatly improves our ability to appraise the range of possible exposure scenarios and environmental risk to aquacultural species and human who consume contaminated fish and shellfish. Probabilistic exposure assessments will substantially reduce the compounded conservatism that is inherent in risk assessments that rely on conservative point value estimates for all biokinetic-and/or toxicological effects-related parameters.

\section{References}

Amiard-Triquet, T.C., Metayer, C., Amiard, J.C., Berthet, B., 1987. In situ and experimental studies of the ecotoxicology of four metals (cadmium, lead, copper, zinc) on algae and grazing gastropod molluscs. Water Air Soil Pollut. 34, 11-30.

Balthis, W.L., Voit, E.O., Meaburn, G.M., 1996. Setting prediction limits for mercury concentrations in fish having high bioaccumulation potential. Environmetrics 7, 429-439.

Bertine, K.K., Goldberg, E.D., 1972. Trace elements in clams, mussels, and shrimp. Limnol. Oceanogr. 17, $877-884$.

Chen, H.C., 1984. Studies on the aquaculture of small abalone, Haliotis diversicolor supertexta, in TaiwanLiao, R., Hirano, R. (Eds.), Proceedings of ROC-Japan Symposium on Mariculture, vol. 1. Tungkang Marine Laboratory, Pintung, Taiwan, pp. 143-159.

Chen, H.C., 1989. Farming the small abalone, Haliotis diversicolor supertexta, in Taiwan. In: Hahn, K.O. (Ed.), Handbook of Culture of Abalone and Other Marine Gastropods. CRC Press, FL, USA, pp. 265-283.

Chen, J.C., Lee, W.C., 1999. Growth of Taiwan abalone Haliotis diversicolor supertexta fed on Gracilaria tenuistipitata and artificial diet in a multiple-tier basket system. J. Shellfish Res. 18, 627-635. 
Conroy, P.T., Hunt, J.W., Anderson, B.S., 1996. Validation of a short-term toxicity test endpoint by comparison with longer-term effects on larval red abalone Holiotis rufescens. Environ. Toxicol. Chem. 15, 1245-1250.

El-Shaarawi, A.H., Viverros, R., 1997. Inference about the mean in log-regression with environmental applications. Environmetrics 8, 569-582.

Finley, B., Proctor, D., Scott, P., Narrington, N., Paustenbach, D., Price, P., 1994. Recommended distributions for exposure factors frequency used in health risk assessment. Risk Anal. 14, 533-553.

Genter, R.B., Lehman, R.M., 2000. Metal toxicity inferred from algal population density, heterotrophic substrate use, and fatty acid profile in a small stream. Environ. Toxicol. Chem. 19, 869-878.

Hahn, K.O., 1989. Biotic and abiotic factors affecting the culture of abalone. In: Hahn, K.O. (Ed.), Handbook of Culture of Abalone and Other Marine Gastropods. CRC Press, FL, USA, pp. 113-283.

Hogstrand, C., Webb, N., Wood, C.M., 1998. Covariation in regulation of affinity for branchial zinc and calcium uptake in freshwater rainbow trout. J. Exp. Biol. 201, 1809-1815.

Hornberger, G.M., Spear, R.C., 1980. Eutrophication in Peel Inlet: I. The problem-defining behaviour and a mathematical model for the phosphorus scenario. Water Res. 14, $29-42$.

Jager, T., den Hollander, A., van der Poel, P., Rikken, G.J., Vermeire, T., 2001. Probabilistic environmental risk assessment for dibutylphthalate. Hum. Ecol. Risk Assess. 7, 1681-1697.

Johnson, R.A., Gan, D.R., Berthouex, P.M., 1995. Goodness-of-fit using very small but related samples with application to censored data estimation of PCB contamination. Environmetrics 6, 341-348.

Knauer, K., Behra, R., Sigg, L., 1997. Effects of free $\mathrm{Cu}^{2+}$ and $\mathrm{Zn}^{2+}$ ions on growth and metal accumulation in freshwater algae. Environ. Toxicol. Chem. 16, 220-229.

Lee, C.L., Chen, H.Y., Chuang, M.Y., 1996. Use of oyster, Crassostrea gigas, and ambient water to assess metal pollution status of the Charting coastal area, Taiwan, after the 1986 green oyster incident. Chemosphere 33, 2505-2532.

Lin, M.C., Liao, C.M., 1999. ${ }^{65} \mathrm{Zn}$ (II) accumulation in the soft tissue and shell of abalone Haliotis diversicolor supertexta via the alga Gracilaria tenuistipitata var. liui and the ambient water. Aquaculture 178, 89-101.

Singhagraiwan, T., Doi, M., 1993. Seed Production and Culture of a Tropical Abalone, Haliotis asinine Linne. The Eastern Marine Fisheries Development Center, Thailand, 31 pp.

Sokal, R.R., Rohlf, F.J. (Eds.), 1995. Biometry, 3rd ed. Freeman, New York, NY, USA, pp. 214-223.

Spear, R., Hornberger, G.M., 1980. Eutrophication in Peel Inlet: II. Identification of critical uncertainties via generalized sensitivity analysis. Water Res. 14, 43-49.

Thompson, R.E., Voit, E.O., Scott, G.I., 2000. Statistical modeling of sediment and oyster PAH contamination data collected at a south Carolina estuary (complete and left-censored samples). Environmetrics 11, 99-119.

Vermeire, T., Jager, T., Janssen, G., Bos, P., Pieters, M., 2001. A probabilistic human risk assessment for environmental exposure to dibutylphthalate. Hum. Ecol. Risk Assess. 7, 1663-1679.

Voit, E.O., Schubauer-Berigan, M.K., 1998. Canonical modeling as a unifying framework for ecological and human risk assessment. In: Newman, M.C., Strojan, C.L. (Eds.), Risk Assessment: Logic and Measurement. Ann Arbor Press, Chelsea, MI, USA, pp. 101-139.

Vose, D., 2000. Risk Analysis: A Quantitative Guide. Wiley, New York, NY, USA.

Zar, J.H. (Ed.), 1999. Biostatistical Analysis, 4th ed. Prentice-Hall, NJ, USA, pp. 132-164. 